\title{
Advances in tissue engineering of the cardiac muscle for myocardial regeneration
}

\author{
Avances en la ingeniería tisular del músculo cardíaco \\ para la regeneración miocárdica
}

Ruiz-de-Almirón-de-Andrés, B.

Estudiante de la Facultad de Medicina. Universidad de Granada

\begin{abstract}
Tissue engineering is currently at the avant-garden of research and aims to build regenerative alternatives in vitro by means of combining a scaffold material, adequate cells and bioactive molecules. It has been 20 years since the initial description of a tissue engineering construct, but in relation to the management of heart disease, these new technologies are not yet fully established, due to the challenges presented by their transfer to the clinic. However, advancements are being made into these therapies, and therefore it necessary, for example, support to academic laboratories, adequate funding, cooperation between different laboratories by coordinating comparable approaches and evidence-based information. Generally, scaffold materials such as gelatin, collagen alginate or synthetic polymers and cardiac cells are used to reconstitute native tissue-like constructs in vitro. They should have propensity to intgrate and remain contractile in vivo. This review aim is to present cardiac tissue engineering strategies for the functional recovery of altered cardiac tissue with a focus on different methods of application, neovascularization, advances in 3D bioprinting and future perspectives.
\end{abstract}

\section{Resumen}

La ingeniería de tejidos está actualmente en la vanguardia de la investigación y tiene como objetivo construir alternativas regenerativas in vitro mediante la combinación de un material de andamiaje, células adecuadas y moléculas bioactivas. Han pasado 20 años desde la primera descripción de una construcción de ingeniería tisular, pero en relación con el manejo de las enfermedades cardiacas, estas nuevas tecnologías aún no están completamente establecidas, por los desafíos que presenta su traslación a la clínica. No obstante, se está progresando con estas terapias y por ello se necesita, por ejemplo, apoyo a los laboratorios académicos, financiación adecuada, cooperación entre los distintos laboratorios mediante la coordinación de enfoques comparados e información basada en evidencia. Generalmente, se utilizan materiales de andamiaje como gelatina, colágeno, alginato o polímeros sintéticos y células cardíacas para reconstuir in vitro constructos similares a los tejidos nativos. Estos deben ser propensos a integrarse y permanecer contráctiles in vivo. El objetivo de esta revisión es presentar las principales estrategias de ingeniería tisular para la recuperación funcional del tejido cardiaco alterado con un enfoque en los distintos métodos, la neovascularización, los avances en la bioimpresión 3D y las perspectivas futuras.
Keywords: Heart failure; Tissue engineering; Biomaterials; Regeneration; Stem cells; Cardiomyocytes.

\begin{abstract}
Palabras clave: Insuficiencia cardiaca; Ingeniería tisular; Biomateriales; Regeneración; Células madre; Cardiomiocitos.
\end{abstract}

\section{INTRODUCTION}

Myocardial infarction (MI) is the outcome of many cardiovascular diseases and heart transplant is actually the only solution for these patients. Althought, stem cell-based therapy has emerged as a promising approach for prompting cardiac rejuvenation, it still has its limitations in terms of the degree of regeneration of the infarcted tissue and the improvement of cardiac function (1). A major problem for cell therapy is the low level of retention of infused or injected cell products. Most studies concur that only few of the transplanted cells survive in the hostile environment of the host tissue, and even fewer integrate and are retained in the host myocardium scar (2). However, transplantation also has its limitations in relation to the lower number of donors or the risk of inmune rejection of the graft. Faced with the need to overcome these obstacles, strategies have emerged over the years focused on restoring complete cardiac function by reconstructing the affected tissue by incorporating within scaffolds cells, wich provide optimal structural, mechanical and physiological properties (3). This field of work is called Tissue Engineering (TE), wich is a multidisciplinary field that combines the principles of 
biology, engineering, chemistry, biotechnology and medicine to artificially construct biological substitutes in order to repair or regenerate damaged tissues (4), (Figure 1).

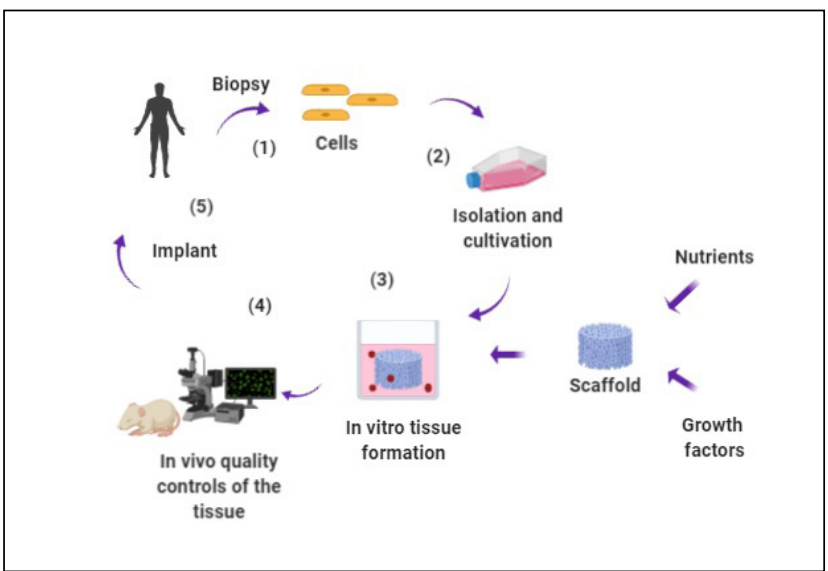

Figure 1. Tissue engineering procedure. 1. Biopsy of the patient to extract cells depending on the tissue to be regenerated; 2. After surgical dissection, the isolation of the cells must be performed by mechanical fragmentation or by enzymatic digestion, so that they can subsequently be cultured in a specific culture medium.; 3. We need a stroma where the cells can be immersed and development in the same way as in their native tissue. Porous scaffold, cells, nutrients and growth factors allow the formation of the tissue in the culture medium; 4. Evaluation of cell viability; and 5. Implant.

To understand that it is a tissue engineering product we have to take into account three components: stem cells, growth factors and scaffolds.

As for cell sources, stem cells are the primary source due to their ability to proliferate and promote tissue regeneration, release a wide range of growth factors and modulate the host inmune response (5). Once we have the cell type, the behaviour and proliferation should be guide either by manipulating the extracellular microenvironment in which the cell is going to develop its activity or by genetically manipulating these cells to modify the synthesis of the extracellular matrix, inhibit the immune response or alter cell proliferation. Regarding the growth factors, the cell response derives from the detection of chemical signals or physical stimulus from the extracellular environment, wich will activate molecular and biological mechanisms responsible for division, migration, differentiation, phenotype maintenance or apoptosis. Therefore, controlling the concentration, local duration and spatial distribution of these factors is essential to their utility and efficacy (6). Lastly, scaffolds are used as structural support for the new microenvironment of the biological substitute. They will allow cell union, migration and differentiation, as well as they favour an organisation to facilitate the action of growth factors and molecular signals (3). In this regard, hydrogels appear to be the most promising biomaterials due to their high hydratation, easy tunning for recreate extracellular matrix (ECM) properties and biocompatibility (7). These properties favour a suitable microenvironment for cell growth, the incorporation of drugs and the controlled release of biologically active agents (8). In order to optimize the physical and mechanical properties of hydrogels, nanoparticles acting as enhancing materials have also been investigated to incorporate into different kinds of natural or synthetic polymer networks to prepare nanocomposite hydrogels for TE (7).

Basic research is essential and subsequently, the translation of these pre-clinical results into clinical practice plays a crucial role. It is necessary the adaptation of the in vitro and in vivo studies, as well as the biofabrication protocols to a good manufacturing practice manufacturing process and the design of an advanced therapy clinical trial obeying European requirements and regulations. In Andalusian there are two successful experience in the development and clinical translation of two tissue enginee- ring products: a novel anterior lamellar artificial cornea (9) and artificial autologous human skin (10). Also, recently Traverse et al. evaluated the safety and feasibility of a cardiac extracellular matrix hydrogel, in early and late post-myocardial infarction patients with left ventricular dysfunction (11)

This review aim is to look over the different strategies, elements and challenge of cardiac tissue engineering in the scientific literature.

\section{SYNTHESIS OF THE REVIEW}

This article discusses the scientific literature on scaffolding strategies for regenerative therapies by means of tissue engineering. It will be analyses the cell sources, important methods of tissue engineering investigated up to know, essential points of neovascularization as well as the 3D bioprinting, and finally the future perspectives towards the achievment of transferring this strategies to the clinic.

\section{Stem cells}

Cells will be responsible for homeostasis and to forming the connections between the tissue matrix and the native tissue. So it is important to choose the cell type by virtue of the objective of the new tissue to be grafted. For this reason, stem cells due to their favourable proliferation characteristics, tissue regeneration, releasion a wide range of growth factors, modulation the host inmune response and serving as feeder platform for ex vivo expansion of differenciated cells (5), are the most studied to promote tissue engineering processes. Stem cells can be allogenic or autologous, but the latter are the central focus of research due to the problems of surveillance and rejection that still present allogenic cells (3). (Table 1 ) shows cells with cardiac regeneration potential.

As we can see, the elaboration of constructs in the laboratory depends mainly on avaibility of viable cells, so viability and physiological state maintained in culture must be previusly studied in order to be able to use them for clinical purposes. Classical methods based on exclusion dyes such as tripan blue are used to identify membrane alterations or the metabolic state of cells. Other protocols to analyse cell viability include a technique using quantitative analytical electron miscroscopy by X-ray emission that allows to identify, localize, and quantify elements both at the whole cell and at the intracellular level $(22,23)$. Likewise, once the tissue substitute has been obtained, it must be analysed and evaluated to guarantee a structure similar to that of the native tissue to be replaced and that normal functions of the native tissue can be reproduced at both in vitro and in vivo levels by the tissue substitutes (24). Thus, the evaluation of cell viability is very important and it is a basic criteria to ensure therapeutic efficacy of tissues and approval as advanced therapy medicament $(9,10)$.

\section{Cardiac Tissue Engineering}

Most common cardiovascular diseases can have as a consequence the formation of non-contractile conjunctive scar tissue, inflammation of the tissue's microenvironment, calcification of the grafts and degradation among others (3). This is why simple repair or regeneration focused on the reconstitution of cardiomyocytes is ineffective, as the lesion interrupts the organization of cardiac tissue and architecture, along with the coordinated interaction of cells. It will be important for the repair or regeneration both restoration of cell types and scaffold structure to restore electrical and mechanical communication between the cardiomyocytes and the environment. Therefore, key points of regeneration are the sources of new cardiomyocytes, the role of inflamatory and inmune cells, extracellular matrix, neovascularization and lymphagenesis (25).

Cardiac tissue engineering objective is to reconstitute the contractile tissue of the myocardial muscle in vitro using synthetic 


\begin{tabular}{|c|c|c|c|c|}
\hline CELL & ADVANTAGES & DISADVANTAGES & REF. & SOURCE \\
\hline Fetal CMs & Potential integration and regeneration & $\begin{array}{l}\text { Ethical issues, limited avaibility and } \\
\text { immunogenicity. Long-term studies } \\
\text { revealed massive cell death and } \\
\text { limited proliferation of the implanted } \\
\text { cells. }\end{array}$ & 12 & Allogeneic \\
\hline $\begin{array}{l}\text { Umbilical } \\
\text { Cord- } \\
\text { Derived } \\
\text { MSCs }\end{array}$ & $\begin{array}{l}\text { Improvements in left ventricular function, } \\
\text { functional status, and quality of life were } \\
\text { observed in patients treated with UC-MSCs }\end{array}$ & $\begin{array}{l}\text { No severe adverse effects were } \\
\text { observed, but preliminary results, } \\
\text { need to be confirmed in larger and } \\
\text { more organized clinical trials }\end{array}$ & 13,14 & Allogeneic \\
\hline $\begin{array}{l}\text { Embryonic } \\
\text { cells }\end{array}$ & $\begin{array}{l}\text { Pluripotent, It has been demonstrated } \\
\text { in a non-human primate model that an } \\
\text { intramyocardial delivery of human ESC- } \\
\text { derived CMs gave re-muscularization of the } \\
\text { infarcted zone }\end{array}$ & $\begin{array}{l}\text { Ethical and legal issues. } \\
\text { Adverse arrhythmic complications }\end{array}$ & 15,16 & Allogeneic \\
\hline AdSCs & $\begin{array}{l}\text { Preclinical studies with AdSCs have shown } \\
\text { improvement in ventricular function in } \\
\text { animal models of MI. Clinical trials in humans } \\
\text { showed only modest beneficial effects on } \\
\text { cardiac function and on myocardial perfusion }\end{array}$ & Low survival & 3,17 & Autologous \\
\hline $\begin{array}{l}\text { Skeletal } \\
\text { myoblast }\end{array}$ & $\begin{array}{l}\text { Positive outcomes by reducing infarct size, } \\
\text { as well as myocardial fibrosis, thwarting } \\
\text { ventricular remodeling and improving overall } \\
\text { cardiac function. }\end{array}$ & Ventricular arrhythmias & 18 & Autologous \\
\hline $\begin{array}{l}\text { BMD stem } \\
\text { cells }\end{array}$ & $\begin{array}{l}\text { Increase of the mean global left ventricle } \\
\text { ejection fraction. }\end{array}$ & $\begin{array}{l}\text { Significant differences among the } \\
\text { trials. The differences made a reliable } \\
\text { comparison of the trials' outcome } \\
\text { and also the reproducibility. }\end{array}$ & 14,19 & Autologous \\
\hline hiPSCs & $\begin{array}{l}\text { In vivo transplantation experiments with } \\
\text { hPSC-CMs have been showed promising } \\
\text { effects of heart regeneration, like progressive } \\
\text { maturation and generate remuscularization of } \\
\text { infarcted heart }\end{array}$ & $\begin{array}{l}\text { Ventricular arrhythmias observed in } \\
\text { transplanted large animals }\end{array}$ & 20 & Autologous \\
\hline $\begin{array}{l}\text { Cardiac } \\
\text { Stem Cells } \\
\text { (CSCs) }\end{array}$ & $\begin{array}{l}\text { Cardiosphere-derived cells have been shown } \\
\text { their ability to promote cardiac regeneration, } \\
\text { reducing the scar size and thickening the wall } \\
\text { of the infarcted zone in a clinical trial. }\end{array}$ & $\begin{array}{l}\text { Limited avaibility. The real } \\
\text { regenerative potential remains } \\
\text { controversial. }\end{array}$ & 21 & Autologous \\
\hline
\end{tabular}

Table 1. Stem cells types used for cardiac tissue engineering

AdSCs: Adipose stem cells-based; BMD: bone marrow-derived stem cells; ESC-derived Cms: Embryonic-stem-cell-derived cardiomyocytes; Fetal Cms: Fetal cardiomyocytes; hiPSCs: human induced pluripotent stem cells; hPSC-CMs: human pluripotent stem cells derived cardiomyocytes; LVEF: left ventricular ejection fraction MI: miocardial infartion; UC-MSCs: Umbilical cord Mesenchymal Stem Cells $(1,3,12-21)$.

or biological matrices and cardiac cells to replace the diseased myocardium in vivo. Tissue must restore basic cardiac functions as well as functional vascularization (26). In addition to the cell type, scaffold and bioactive molecules, consideration should be given to the bioreactor where the artificial tissue is grown under controlled conditions (3). Thus, the ideal construct should be contractile, allowing physiological electrical propagation, mechanically robust, but flexible, vascularized or capable of rapid vascularization after implantation, non-inmunogenic and with good biodegradability $(3,27)$.

Currently researches are addressing different methods of tissue engineering: biomimetic scaffolds, hydrogels, decellularized scaffolds and cell sheets. All of them are trated below.

\section{a) Biomimetic scaffolds}

A biomimetic biomaterial can be any scaffolding material that mimics the characteristics of the natural ECM. They are based on polymers that may be natural, synthetic or biosynthetic $(26,28)$. They are interesting for the repair and regeneration of tissues due to their biodegradability, mechanical properties or high porosity. Porosity is it very important in terms of structure functionality because it allows cell infiltration and colonization of the extracellular matrix improving cell growth, proliferation and migration, as well as efficient cell adhesion and diffusion, tissue vascularization and tissue formation. So, scaffolds should allow the transport of the nutrients needed to the cell attachment, proliferation and differentiation, stimulation of cell-biomaterial 
attachment, growth and migration, mechanical support and a controlled degradation rate with no toxicity or inflammation risk to the cells (10).

Naturals polymers shows biological properties that better fit to the regular microenvironment of tissues, promoting desirable cellular response, biocompatibility and degradability. They are derived from biological sources and the most common materials in cardiac tissue engineering are collagen and gelatin (derived from mammalian extracellular matrix) and alginate. The use of natural materials has been expanded through incorporation into co-polymer structures with synthetic biomaterials, such as polycapralactone and poly-L-lactic acid, or chitosan for improvement of scaffold or hydrogel properties. As for the synthetic polymers are an attractive alternative to natural materials because they have the ability to control the entire synthesis procedure, their mechanical properties, topography and structure of the material. Consequently, they are preferred for in vivo applications to allow for the engineered tissue to integrate and minimize adverse host response. The most notable polyesters are FDA-approved polycapralactone, poly-L-lactic acid, and poly(lactic-co-glycolic acid), which have been applied in many tissue engineering applications (29). It is essential to use biocompatible and biodegradability gels in order to avoid both long-term bioreactions and toxic inflammatory reactions (30).

Biomimetic scaffold can be used alone as acellular scaffolds or in combination with cells (31) and generally must be non-inmunogenic, mechanically stable and flexible, allow physiological electrical propagation and nutrients to the cells, and have biodegradability rate. When combined with cells (Table 2) they may improve the retention of transplanted cells as well as increase cell survival. Injection of acellular scaffolds with or without bioactive molecules aids in structural mechanic support, decrease of fibrosis and ventricular dilation, as well as promotes recruitment of native stem cells and angiogenesis $(26,32)$. Recently, McLaughlin et al. have reported the first injectable biomaterials made from recombinant human collagens type I $(\mathrm{rHCl})$ and type III ( $\mathrm{rHClII})$, instead of using animal-derived components. After pre-clinical performance in a well-established mouse model of $\mathrm{MI}$, their results highlight the potential for a biomaterial based on human recombinant collagen to be used as therapy for the improvement of cardiac function post-MI (33).

\section{b) Hydrogels}

Hydrogels are the most commonly used polymers in tissue engineering and exactly they are the natural extracellular matrix protein collagen I, mixtures of collagen I and matrigel and the blood-clotting material fibrin $(32,34,35)$. The elasticity and swelling properties of hydrogels make them desirable for injectable purposes and bioprinting applications. Pororsity and mechanical properties are also important in terms of biocompatibility and structural similarity to the native ECM (10).

Already in the 90s, Eschenhagen et al. (36) succeeded in obtaining three-dimensional heart tissue developing a method for cultivating cardiomyocytes in a collagen matrix and allowed them to gel between two Velcro-coated glass tubes. This opened up the possibility of being able to study in vitro the functional consequences of genetic or pharmacological manipulation of cardiomyocytes under highly controlled conditions.

Some research groups have developed a natural and biodegradable hybrid composed by human fibrin and agarose type VII, a polysaccharide originating from algae (FAH). It has been applicated in the construction of different engineered tissues like cornea (37), skin (38), oral mucosa (24) and peripheral nerve (39) among others, and they have shown that the nanostructuration and cross-linking techniques improved the biomechanical and structural properties of different biomaterials.

\section{IN VITRO ENGINEERED TISSUE \\ IN SITU ENGINEERED TISSUE}

Gelatin $\rightarrow$ Alone or with fetal cardiomyocytes

Alginate $\rightarrow$ With fetal cardiomyocytes

Alginate and matrigel $\rightarrow$ w/SDF-1, IGF-1 and VEGF w/Neonatal $\mathrm{CM}+$ SDF-1, IGF-1 and VEGF

Poly(glycolide)/poly(lactide) $\rightarrow$ With dermal fibroblasts

Collagen type I and matrigel $\rightarrow \mathrm{w} / \mathrm{SkM}$

PTFE, PLA mesh, collagen type I and matrigel $\rightarrow$ Alone or w/ hBMC-derived MSCs

Collagen type I $\rightarrow$ Alone or w/BMC, HUCBCs, hBMC CD133+, hMSC, hSkM.

PNIPAAM (cell culture dish) $\rightarrow$ Cell sheet of neonata $\mathrm{CM}$ or adipose-derived MCSs

Decellularized myocardium/fibrin $\rightarrow$ w/mesenchymal

progenitor cells

Pericardium $\rightarrow \mathrm{w} / \mathrm{MSC}$

Fibrin $\rightarrow$ Alone or with BMCs, ASCs, MCSCs, BMMNCs w/bFGF, HGF, TGF $\beta-1$

Alginate $\rightarrow \quad$ Alone, PDGF-BB, IGF-1, HGF w/hMSCs or w/Polypyrrole

Collagen $\rightarrow$ Alone or w/BMC

Hyaluronic acid $\rightarrow$ Alone

Myocardial and Pericardial matrix $\rightarrow$ Alone

Alginate $\rightarrow$ Alone or w/VEGF, PDGF-BB, IGF-1, HGF w/hMSCs or w/Polypyrrole

Matrigel $\rightarrow$ Alone or w/ ESC

Collagen type I and matrigel $\rightarrow$ Alone or $\mathrm{w} /$ neonatal $\mathrm{CM}$

Self-assembling peptides $\rightarrow$ Alone or $w /$ nenonatal CM, PDGF-BB

Gelatin $\rightarrow$ Alone or w/bFGF

Calcium hydroxyapatite $\rightarrow$ Alone

Chitosan $\rightarrow$ Alone or w/ ESCs, bFGF, neonatal CM w/Polypyrrole

Table 2. Main biomaterials researched for treatment of MI.

ASC: adipose-derived stem cell; bFGF: basic fibroblast growth factor; BMC: bone marrow cell; BMMNC; bone marrow-derived stem cell; CM: cardiomyocyte; ESC: embryonic stem cells; HGF: hepatocyte growth factor; HUCBC: human umbilical cord blood mononuclear cell; MSC: mesenchymal stem cell; IGF: insulin-like growth factor; PDGF: platelet-derived growth factor; PLA: poly (L-lactic) acid; PNIPAAM: poly (N-isopropylacrylamide); PTFE: poly (tetrafluoroethylene); SDF: stromal cell-derived factor; SkM: skeletal myoblast; TGF: transforming growth factor; VEGF: vascular endothelial growth factor. (Adapted from ref. 31). 
For cardiac tissue engineering, it is crucial the development of electrically conductive hydrogels to achieve the spontaneous beating behaviour of the heart, in order to accomplished the functional regeneration $(8,40)$.

Advances in the science and applications of hydrogel systems have led to develop 'smart hydrogels', which are polymeric scaffolds with tunable properties. They can be triggered by certain stimulus such as temperature, electric and magnetic fields, light, $\mathrm{pH}$, ions, and specific molecular recognition events such as glucose. These polymers can exhibit dramatic changes in their swelling behavior, sol-gel transition, network structure, permeability, or mechanical strength in response to changes in the $\mathrm{pH}$, ionic strength, or temperature, as an example (41).

Newly, there are some contributions about hydrogels. First one, shows up an injectable nanocomposite hydrogel, which could be potential for vascularization and tissue repair aplicattions. It has been developed with chitosan, gelatin, $\beta$-glycerphosphate and Arg-Gly-Asp (RGD) peptide and loaded with stromal cell-derived factor-1 and vascular endothelial growth factor (VEGF) nanoparticles to simulate the natural nanoparticles in the extracellular matrix to promote angiogenesis (42). Secondly, an injectable human amniotic membrane (hAM) matrix (43). And, lastly is about the first-in-man clinical trial performed with an extracellular matrix hydrogel derived from decellularized porcine myocardium (Ventrigel), in post-MI patients. After preclinical studies showing biocompatibility, hemocompatibility, and lack of arrhythmias, a multicenter trial was developed to evaluate the safety, feasibility, and preliminary efficacy of percutaneous transendocardial delivery of VentriGel in early and late MI patients with left ventricular dysfunction (11).

\section{c) Decellularized scaffolds}

Decellularized extracellular matrices (dECM) processed in vitro could be promising biomaterials for cardiovascular tissue regeneration as it has the potential to overcome the need to artificially recreate the conditions from ECM deposition (35). They most effectively captures the complex array of proteins, glycosaminoglycans, proteoglycans, and many other matrix components that are found in native tissue, providing ideal cues for regeneration and repair of damaged myocardium. In addition, dECM can be used either as solid scaffolds that mantain the native matrix structure, or as soluble materials that can form injectable hydrogels for tissue repair and regeneration (44). For decellularization and subsequent recellularization are required a scaffolding organ; a detergent, osmolar or enzymatic solution to remove native cell material; stem cells for repopulation; and a culture environment, or bioreactor, to promote adhesion, growth and integration of new cells (3). Generally, decellularization performed by perfusion with SDS or Triton X-100 has been done successful in small animal organs and whole organs. This procedure wipes out almost completely cells from the tissue but leaves connective tissue architecture of blood vessels intact and most of the components of the extracellular fibrillar and non-fibrillar matrix, so it allows perfusing of the remaining matrix $(44,45)$. For cardiovascular treatment dECM materials have been limited to repair or replacement of heart valves, large vasculature, and congenital heart defects using patches and valves (PhotoFix, CryoValve), pericardial patches (SJM and Tutopatch) and injectable cellular ECM hydrogels with soluble ECM (Ventrigel) (44).

Recently, it have been developed two engineered cardiac grafts based on decellularized scaffolds from myocardial and pericardial tissues. They were repopulated with adipose tissue mesenchymal stem cells. It was observed that decellularized scaffolds maintained structural integrity of the native matrix fibrils (Figure $2 A, B, G, H$ ) and type-I and type-III collagens, were properly marked, indicating preservation of matrix protein components (Figure $2 \mathrm{~J}, \mathrm{~K}$ ). After recellularization it was confirmed the capability to recruit cells (Figure $2 C, I, F, L)$. The mechanical properties of cardiac tissue were evaluated and no significant changes were found when comparing data along the different recellularization steps. Comparative analysis of the generated acellular myocardial and pericardial tissues revealed they shared $40 \%$ of the matrisome proteins, wich are involved in cellular processes such as maintaining the ECM structure and modulating cell differentiation (coIlagens type-I, -III, -IV, -V, -VI), cell adhesion (laminin family and heparan sulfate), or survival and differentiation processes (fibronectin). Immunohistological analysis showed correct adhesion of the implanted graft with myocardium and hystological analysis showed functional blood vessels connected to host vascularization in all scaffolds of the experimental groups. Both engineered cardiac grafts were further evaluated in pre-clinical MI swine models and demonstrated biocompability and efficacy, improving ventricular function, as well as integration with the underlying myocardium and signs of neovascularization and nerve sprouting (46). At this moment, it is going under an interventional clinical trial (PeriCord) and it is based on a decellularized pericardial matrix with mesenchymal stem cells that carries them directly over myocardial infarction.

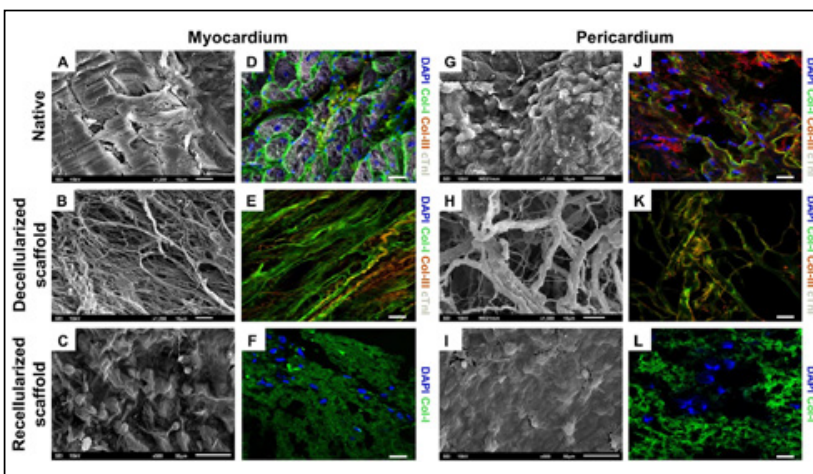

Figure 2. Internal structure and protein composition of the cardiac scaffolds. SEM images of the (A) native myocardium, (G) native pericardium, (B) decellularized myocardial scaffold and $(\mathrm{H})$ decellularized pericardial scaffolds, showing the intrinsical organization and spatial three-dimensional distribution of the native matrix fibrils. Native myocardium and decellularized myocardial scaffolds, respectively (D,E) and $(\mathrm{J}, \mathrm{K})$ native pericardium and decellularized pericardial scaffolds showing immunostaining for matrix proteins, type-I (green) and type-III (red) collagens and cardiac troponin I, cTnI (white). (C) recellularized myocardial and (I) pericardial scaffolds, showing the presence of cells detected using SEM and $(\mathrm{F}, \mathrm{L})$ displaying immunostaining for col-I (green) for recellularized myocardial and pericardial scaffolds. Nuclei were counterstained with DAPI (b/ue). Scale bars $=50 \mu \mathrm{m}$. Reproduced from Perea-Gil et al ${ }^{46}$ with permission of the publisher. Copyright (c) 2018, Springer Nature. Creative Commons license: http://creativecommons.org/licenses/ by/4.0\%.

\section{d) Cell sheets}

This technique is based on the construction of cell sheets without scaffolding using specialized temperature-responsive polymer surfaces, wich allow to binding of cells, and the deatachment of the cultured cells as an intact layer without altering the deposited $\operatorname{ECM}(2,34)$. In that respect, previously Inui \& Sekine et al. showed up that cocultivation with vascular endothelial cells (Figure $3 \mathrm{~A})$, treatment with vascular endothelial growth factor (VEFG) and in vitro vascularization bioreactors may favour the stacking of three-layers laminae in several stages. Recently they have been developed a new method involved the layering of cardiac cell sheets derived from human induced pluripotent stem cells cocultured with endothelial cells and fibroblasts on a vascular bed derived from porcine small intestinal tissue (Figure 3B,C). They succeeded in engineering spontaneously beating $3 \mathrm{D}$ cardiac tissue 
in vitro. The bioengineered cardiac tissue was transplanted into another pig and observed to beat spontaneously after reperfusion with blood, but waiting for immunogenicity, sterility and scalability responses (47).

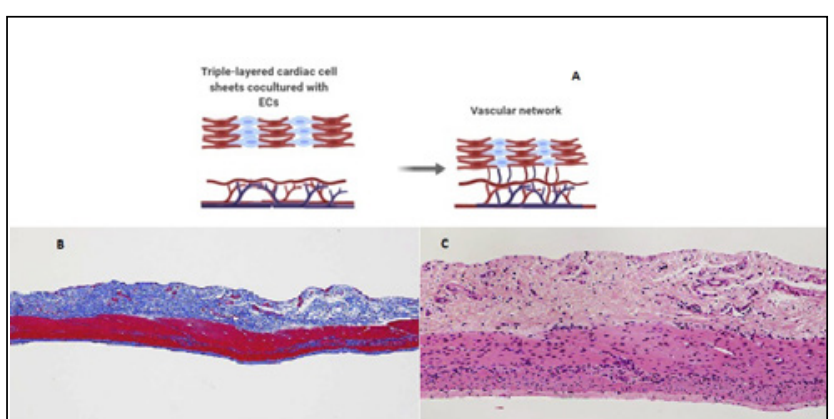

Figure 3. Cell-sheet onto a vascular bed. (A) Endothelial cells (ECS) cocultured cardiac cell sheets are stacked. Then overlaid on a vascular bed in vitro and after appropriate perfusion using a bioreactor, the cocultured ECs formed new blood vessels and connected with the blood vessels that originated from the vascular bed. (B) Vascular bed created from porcine small intestine. Histological analysis with Azan trichrome staining revealed the adequate resection of the mucosa and the preservation of the extracellular matrix and small vessels (before vessels perfusion) without damage to the tissue. (C) Hematoxylin-eosin staining confirmed that the tissue had not been damaged by mucosal resection and cell nuclei were present throughout the remaining tissue (before perfusion culture). (B) and (C) reproduced from Inui et al 47 with permission. Copyright (C) 2019, The Japanese Society for Regenerative Medicine. https://creativecommons.org/ licenses/by-nc-nd/4.0/

\section{Neovascularization and Lymphangiogenesis}

After a myocardial injury, the vascularization plays a crucial rol to allow tissue engineering constructs to survive and grow. It is essential to overcome the challenging of neovascularization in $\mathrm{TE}$, which aim is similar as much in ischemic disease and in peripheral vascular disease. Therefore, results in therse areas are important for the clinical aplicaction of angiogenesis in tissue engineerring. Angiogenesis is te formation of new vessels from pre-existing vessels and vasculogenesis is the formation of vessels fron endothelial progenitor cells. This two strategies have been approached by reserchers to overcome the inadequate vascularization $(48,49)$. The mechanisms of neovascularization are not yet well defined, but it has been proposed that the epicardium is reactived after the injury and secretes classical angiogenic factors (VEGF, CXCL12, C-X-C motif chemokine 12, or SDF-1), fibroblast growth factor, and retinoic acid. These factors would promote the epithelial-to-mesenchymal transition of epicardium-derived cells that invade the underlying myocardium, giving rise to pericytes, smooth muscle cells and fibroblasts (25).

On the one hand, strategies for improving local circulation could be induce angiogenesis by manipulating pro-angiogenic growth factors. Other alternatives have been proposed such as combining endothelial cells with tissue-specific cells on a scaffold before transplantation to improve the prevascularize of the graft or target site before implantation. On the other hand, hypoxia may have certain advantages. Under hypoxic conditions carries out its function and regulates gene expression of VEGF and stromal cell-derived factor (SCDF-1). SCDF-1 binds to the receptor CXCR4 acting as a chemokine and attracts stem cells, including circulating endothelial progenitor cells, to areas of hypoxia (48).

As far as the lymphatic system, it is important for tissue fluid homeostasis and trafficking of inmune cells. It has been described above that inflamation can activates regenerative pathways and in rodent it has been observed that an induction of lymphangiogenesis with with VEGF-C (vascular endothelial growth factor $\mathrm{C}$ ) improves healing, reduces fibrosis, and preserves myocardial function after myocardial infarction (25).

\section{D Bioprinting}

Construction of a vascular organ like heart is still being a challenge, as well as the synchronization of synthesized tissue constructs with native tissue and execution of spontaneous contraction. Recently, once of the most important technological advances is 3D bioprinting. This strategy provides an alternative to develop a heterogeneous 3D scaffold with strong mechanical strength and with all required characteristics of an ideal scaffold for cardiac tissue engineering. There are two main categories of 3D printing processes: scaffold-based printing and scaffold-free printing. First one, preprinting of scaffold and then cell layers printing or simultaneous printing of biomaterials and cells. Second one, bioink consists of individual cells or tissue spheroids are used for direct printing on substrate (50). Noor et al. have demonstrated an approach for engineering personalized tissues and organs using non supplemented materials as bioinks for 3D bioprinting (Figure 4). They reported on the potential of 3D bioprinting to engineer vascularized cardiac patches that fully match the anatomical structure, the biochemical and cellular components of any individual. Furthemore, cellularized hearts with a natural architecture were engineered, demonstrating the potential for organ replacement or for drug screening in an appropriate anatomical structure. However, it is necessary to perform further in vitro studies and in vivo implantation experiments in animal models (51), and to consider the heterogeneity of the polymeric materials selected as bioinks, but also the influence the cell material dynamisms in the printing process because the shear stress caused during the bioprinting also affects cell viability and integrity (8).

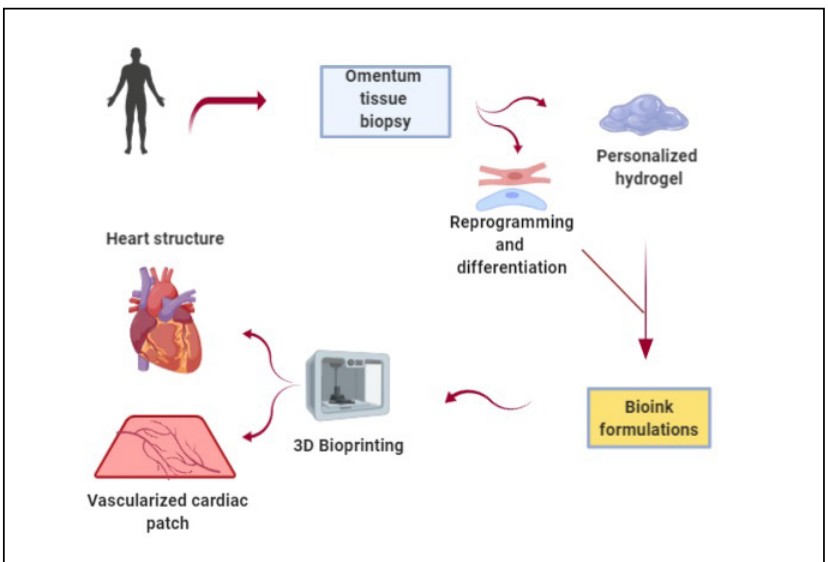

Figure 4. Personalized 3D bioprinting. It is extracted an omentum tissue from the patient. Cells are separated from the matrix, reprogrammed to become pluripotent and differenciated to cardiomyocytes and endothelial cells. The matrix is processed into a personalized hydrogel. Then, cells and personalized hydrogel are encapsulated to generate bioinks in order to printed them to engineer vascularized patches and complex cellularized structures (51).

Another emerging technology with promising advances is organs-on-a-chip (OOAC), which are miniature tissues and organs grown in vitro that enable modeling of human physiology and disease. OOAC offer a promising approach to emulate human patho/physiology in vitro, drug development, disease modeling, and precision medicine (52). Microfluidics devices like organ-on-a-chip and lab-on-a-chip could be a potential technique to observe a real-time effect of biochemical, mechanical, and electrical stimulations on new heart tissue constructs to improve tissue functions (50). 
In spite of these advances, it is needed in the future to integrate all conventional 3D tissue engineering techniques (3D scaffold fabrication techniques, hydrogels, nanofibers, and deceIlularization) with modern scaffold-free 3D bioprinting to achieve the most realistic functional heart (50).

\section{OUTLOOK AND CONCLUSIONS}

Tissue engineering is essential for the construction of artificial tissues, disease modeling and drug screening. Its objective was traditionally and it still is to provide in vitro functional tissues by mimicking the native ECM composition and structure.

Main current challenges are the inconsistency of the rodents hearts studies due to the substantial differences in the cardiac physiology of these with to human heart. Thus, testing has to be performed in animals with a cardiac physiology closer to that of humans and it is necessary improved the TE strategies to increase cell retention. $(34,53)$. Actually, the use of tissue-engineered constructs for myocardial regeneration is still in the preclinical phase, with some exceptions (reflect on ref. 53).

To date, there are several important points. Firstly, cardiac tissue engineering offers teorical advantages over cell therapy such as better cell retention or a controlled environment, and myocardial regeneration must be considered as a global and balanced process involving both cells and other cardiac structures. Electromechanical cellular coupling within the matrix is fundamental to restore cardiac function and the vascularization of the artificial tissue will determine its own viabilty and integration with the host tissue. The benefits of an acellular injectable biomaterials are being disscused because they suggest promoting angiogenesis in preclinical models and have been demostrated to prevent adverse remodeling after myocardial infarction, but nevertheless some randomized trials with natural biomaterial alginate have failed to provide functional benefits. It is important to optimize the selection of appropriate biomaterials and processes for further studies in vitro and in vivo focused on how to achieve an adequate in vitro vascularization and perfusion of engineered constructs for generation large tissue construct to replace a scar and to create appropriate models to test safety and efficacy of human heart engineered tissue (25).

Secondly, as for the challenges presented by hydrogels, it has been improved theirs physical-chemical properties such as stiffness, porosity, degradability and cell adhesion properties among others, to fabricate complex biomimetic architectures for specific tissue regeneration. Combining these hydrogels with stem cell technologies and optimized physical-chemical cues will further allow for the mimicking of the dynamic regeneration-stage specific microenvironment $(8,42,43)$. And finally, pure decellularized extracellular matrices (dECM) materials have been shown to improve cardiac functionality in a large animal models post-MI or ischemia, with improved angiogenesis, reduction in inflammatory response, increased progenitor cell recruitment, and stimulation of positive remodeling. So, combined pure dECM materials with cells, additional biomaterials, or paracrine factors suggest an approach based on combinational therapies $(35,46)$.

In conclusion, the complexity of the biological processes in regeneration are evident and some quentions remain hidden. Although cardiac tissue engineering is not one of the most active areas of research compared to bone tissue engineering or skin tissue engineering, it has been made considerable progresses in this field with satisfactory results in some clinical studies showing many benefits. Hydrogel-based matrices seem like interesting biomaterials for engineered tissue scaffolds due to their similarity to native ECM and advanced nanotechnologies have enabled to improve the properties of hydrogels. Also, dECM has received a considerable interest because of it preserves the native tissue composition, and 3D bioprintings human tissues of disease may improve the efficacy of regenerative medicine strategies and enhance the translation to the clinic of promising approaches. Re- garding the transfer to the clinic, since the development of these tissue engineering products is mainly carried out at universities and public hospitals, the support of non-comercial clinical trials and multidisciplinary groups is essential to facilitate tranferring basic research to the clinic.

\section{REFERENCIAS BIBLIOGRÁFICAS}

1. Micheu MM. Moving forward on the pathway of cell-based therapies in ischemic heart disease and heart failure - time for new recommendations? World J Stem Cells. 2019 Aug $26 ; 11(8): 445-451$

2. Madonna R, Van Laake L, Botker H.E et al. ESC Working Group on Cellular Biology of the Heart: position paper for Cardiovascular Research: tissue engineering strategies combined with cell therapies for cardiac repair in ischaemic heart disease and heart failure. Cardiovasc Res. 2019 Mar 1; Vol. 115, Issue 3, pp. 488-500.

3. Alrefai MT, Murali D, Paul A, Ridwan KM, Connell JM, ShumTim D. Cardiac tissue engineering and regeneration using cellbased therapy. Stem Cells Cloning. 2015 May 14;8:81-101

4. Langer R, Vacanti JP. Tissue engineering. Science. 1993 May 14; Vol. 260, Issue 5110, pp. 920-926

5. Carriel V, Geuna S, Alaminos M. Ex Vivo and In Vivo Stem Cells-Based Tissue Engineering Strategies for Their Use in Regenerative Medicine. Stem Cells Int. $2018 \mathrm{Apr}$ 15;2018:7143930

6. Campos A. Cuerpo, histología y medicina: de la descripcción microscópica a la ingeniería tisular. Discurso de ingreso Real Academia Nacional de Medicina, 2004, Madrid.

7. Li X, Sun Q, Li Q, Kawazoe N, Chen G. Functional Hydrogels With Tunable Structures and Properties for Tissue Engineering Applications. Front Chem. 2018 Oct 22;6:499.

8. Pina S, Ribeiro VP, Marques CF, et al. Scaffolding Strategies for Tissue Engineering and Regenerative Medicine Applications. Materials (Basel). 2019 Jun 5;12(11):1824

9. Rico-Sánchez L, Garzón I, González-Andrades M, et al. Successful development and clinical translation of a novel anterior lamellar artificial cornea. J Tissue Eng Regen Med. 2019;13(12):2142-2154

10. Egea-Guerrero JJ, Carmona G, Correa E. et al. Transplant of Tissue-Engineered Artificial Autologous Human Skin in Andalusia: An Example of Coordination and Institutional Collaboration. Transplant Proc. 2019; Vol. 51, Issue 9, pp. 3047-3050

11. Traverse JH, Henry TD, Nabil D. First-in-Man Study of a Cardiac Extracellular Matrix Hydrogel in Early and Late Myocardial Infarction Patients. JACC Basic Transl Sci. 2019 Oct;4 (6) 659-669

12. Li RK, Jia ZQ, Weisel RD. et al. Cardiomyocyte transplantation improves heart function. Ann Thorac Surg. 1996 Sep;62(3):654-60; discussion 660-1.

13. Bartolucci J, Verdugo FJ, González PL. et al. Safety and Efficacy of the Intravenous Infusion of Umbilical Cord Mesenchymal Stem Cells in Patients With Heart Failure: A Phase 1/2 Randomized Controlled Trial (RIMECARD Trial [Randomized Clinical Trial of Intravenous Infusion Umbilical Cord Mesenchymal Stem Cells on Cardiopathy]). Circ Res. 2017 Oct 27;121(10):1192-1204

14. Ghiroldi A, Piccoli M, Cirillo F. et al. Cell-Based Therapies for Cardiac Regeneration: A Comprehensive Review 
of Past and Ongoing Strategies. Int J Mol Sci. 2018 Oct 16;19(10):3194

15. Liu YW, Chen B, Yang $X$. Human embryonic stem cellderived cardiomyocytes restore function in infarcted hearts of non-human primates. Nat Biotechnol. 2018 Aug;36(7):597-605. Erratum in: Nat Biotechnol. 2018 Sep 6;36(9):899

16. Chong JJ, Yang X, Don CW. et al. Human embryonic-stemcell-derived cardiomyocytes regenerate non-human primate hearts. Nature. 2014;510:273-277

17. Qayyum AA, Mathiasen AB, Mygind ND. et al. Adiposederived stromal cells for treatment of patients with chronic ischemic heart disease (mystromalcell trial): A randomized placebo-controlled study. Stem Cells Int. 2017;2017:5237063.

18. Samak M, Hinkel R. Stem Cells in Cardiovascular Medicine: Historical Overview and Future Prospects. Cells. 2019 Nov 27;8(12):15-30.

19. Traverse JH, Henry TD, Pepine CJ. et al. Effect of the use and timing of bone marrow mononuclear cell delivery on left ventricular function after acute myocardial infarction: The time randomized trial. JAMA. 2012;308:2380-2389

20. Jiang Y, Lian XL. Heart regeneration with human pluripotent stem cells: Prospects and challenges. Bioact Mater. 2020 Jan 14;5(1):74-81

21. Lian X, Zhang J, Azarin SM. et al. Directed cardiomyocyte differentiation from human pluripotent stem cells by modulating wnt/beta-catenin signaling under fully defined conditions. Nat. Protoc. 2013;8:162-175

22. Alaminos M, Sánchez-Quevedo MC, Múñoz-Ávila Jl. et al. Evaluation of the viability of cultured corneal endothelial cells by quantitative Electron Probe X-Ray Microanalusis. J. Cell. Physiol. 2007, 211:692-698

23. Garzón I, Perez-Kohler B, Garrido-Gómez J. et al. Evaluation of the cell viability of human Wharton's jelly stem cells for use in cell therapy. Tissue Eng. Part C Methods.2012 Jun;18(6):408-19

24. Alaminos M, Garzón I, Sánchez-Quevedo MC. et al. Timecourse study of histological and genetic patterns of differentiation in human engineered oral mucosa. J Tissue Eng. Regen. Med. 2007; 1: 350-359

25. Shamagian LD, Madonna R, Taylor D. et al. Perspectives on Directions and Priorities for Future Preclinical Studies in Regenerative Medicine. Circulation Research. 2019 March 15; vol. 124, Issue 6, pp. 938-951

26. Xu Y, Chen C, Hellwarth PB, Bao X. Biomaterials for stem cell engineering and biomanufacturing. Bioact Mater. 2019 Dec 2;4:366-379

27. Saberi A, Jabbari F, Zarrintaj P, Saeb MR, Mozafari M. Electrically Conductive Materials: Opportunities and Challenges in Tissue Engineering. Biomolecules. 2019 Sep $4 ; 9(9): 448$

28. Tomov ML, Gil CJ, Cetnar A. et al. Engineering Functional Cardiac Tissues for Regenerative Medicine Applications. Curr Cardiol Rep. 2019;21:105

29. Huyer LD, Montgomery M, Zhao Y, et al. Biomaterial based cardiac tissue engineering and its applications. Biomed Mater. 2015;10(3):034004

30. Somekawa S, Mahara A, Masutani K, Kimura Y, Urakawa $\mathrm{H}$, Yamaoka T. Effect of Thermoresponsive Poly(L-lactic acid)-poly(ethylene glycol) Gel Injection on Left Ventricular Remodeling in a Rat Myocardial Infarction Model. Tissue Eng Regen Med. 2017 Jul 31;14(5):507-516

31. Rane-MS A, Christmann KL. Biomaterials for the Treatment of Myocardial Infarction: A 5-Year Update. J am Coll Cardiol. Vol. 58, Issue 25,2011 , pp. 2615-2629

32. Peña $B$, Laughter $M$, Jett $S$, et al. Injectable Hydrogels for Cardiac Tissue Engineering. Macromol Biosci. 2018;18(6):e1800079

33. McLaughlin S, McNeill B, Podrebarac J. et al. Injectable human recombinant collagen matrices limit adverse remodeling and improve cardiac function after myocardial infarction. Nat Commun. 2019;10: 4866

34. Hirt MN, Hansen A, Eschenhagen T. Cardiac Tissue Engineering State of the Art. Circ Res. 2014;114:354-367

35. Weinberger F, Mannhardt I, Eschenhagen T. Engineering Cardiac Muscle Tissue A Maturating Field of Research. Circ Res. 2017;120:1487-1500

36. Eschenhagen T, Fink C, Remmers U. et al. Three-dimensional reconstitution of embryonic cardiomyocytes in a collagen matrix: a new heart muscle model system. FASEB J. 1997 Jul;11(8):683-94

37. Alaminos M, Sánchez-Quevedo MC, Muñoz-Ávila Jl. et al. Construction of a complete rabbit cornea substitute using a fibrin-agarose scaffold. Invest Ophthalmol Vis Sci. 2006, 47:3311-3317

38. Carriel V, Garzón I, Jiménez JM. et al. Epithelial and Stromal Developmental Patterns in a Novel Substitute of the Human Skin Generated with Fibrin-Agarose Biomaterials. Cells Tissues Organs. 2012;196(1):1-12

39. Carriel V, Scionti G, Campos F. et al. In vitro characterization of a nanostructured fibrin agarose bio-artificial nerve substitute. J Tissue Eng Regen Med. 2017;11: 1412- 1426

40. Baei P, Hosseini M, Baharvand H, Pahlavan S. Electrically conductive materials for in vitro cardiac microtissue engineering. J Biomed Mater Res. 2020; 1- 11

41. Mantha S, Pillai S, Khayambashi P. et al. Smart Hydrogels in Tissue Engineering and Regenerative Medicine. Materials. 2019;12:3323

42. Ding Y, Zhao A, Liu T. et al. An Injectable Nanocomposite Hydrogel for Potential Application of Vascularization and Tissue Repair. Ann Biomed Eng. 2020. [Epub ahead of print]

43. Henry, J, Delrosario L, Fang J. et al. Development of Injectable Amniotic Membrane Matrix for Postmyocardial Infarction Tissue Repair. Adv. Healthcare Mater. 2020; 9:1900544

44. Bejleri D, Davis ME. Decellularized Extracellular Matrix Materials for Cardiac Repair and Regeneration. Adv. Healthcare Mater. 2019; 8:1801217

45. Oliveira AC, Garzón I, Ionescu AM. et al. Evaluation of Small Intestine Grafts Decellularization Methods for Corneal Tissue Engineering. PLOS ONE. 2013;8(6): e66538

46. Perea-Gil I, Gálvez-Montón C, Prat-Vidal C. et al. Head-to-head comparison of two engineered cardiac grafts for myocardial repair: From scaffold characterization to pre-clinical testing. Sci Rep. 2018 Apr 30;8(1):6708. Creative Commons license: http://creativecommons.org/licenses/by/4.0/.

47. Inui A, Sekine $H$, Sano K, et al. Generation of a large-scale vascular bed for the in vitro creation of three-dimensional 
cardiac tissue. Regen Ther. 2019 Oct 22;11:316-323.

Creative Commons license: https://creativecommons.org/ licenses/by-nc-nd/4.0/

48. Chung JC, Shum-Tim D. Neovascularization in tissue engineering. Cells. 2012 Dec 11;1(4):1246-60

49. Tsuji-Tamura K, Ogawa M. Morphology regulation in vascular endothelial cells. Inflamm Regen. 2018 Sep $10 ; 38: 25$

50. Qasim M, Haq F, Kang MH, Kim JH. 3D printing approaches for cardiac tissue engineering and role of immune modulation in tissue regeneration. Int J Nanomedicine. 2019 Feb 20;14:1311-1333

51. Noor N, Shapira A, Edri R, Gal I, Wertheim L, Dvir T. 3D Printing of Personalized Thick and Perfusable Cardiac Patches and Hearts. Adv. Sci. 2019; 6: 1900344

52. Wu Q, Liu J, Wang X. et al. Organ-on-a-chip: recent breakthroughs and future prospects. Biomed Eng Online. 2020 Feb 12;19(1):9

53. Micheu MM. Moving forward on the pathway of cell-based therapies in ischemic heart disease and heart failure - time for new recommendations? World J Stem Cells. 2019 Aug $26 ; 11(8): 445-451$ 